fortunately there are trees growing at a short distance from it, which would entirely check the free circulation of air about the instruments were the screen set up at the usual elevation of about 6 feet above the ground.

Accordingly the window on the second story of the building was selected. It affords a free exposure to the north, but is at a level of $4 \mathrm{I} \mathrm{ft}$. above the ground, and about 87 feet above the sea level.

This elevation will of course exert a considerable influence on the thermometrical observations recorded.

FALMOUTH. - The establishment of an observatory at this station was beset with considerable difficulties; the building in which the Royal Cornwall Polytechnic Society holds its meetings was unsuited to the purposes of a meteorological station. Accordingly a tower was erected at the south-east corner of the bowling green, on the top of one of the hills on which the town is built.

The anemograph is on the summit of the tower, well exposed on all sides; but from the fact that the ground in the neighbourhood is uneven, the hill sloping rapidly down to the harbour, it seems probable that the force of the wind is not quite true, especially when it is easterly.

The position of the thermograph screen is far from being quite satisfactory ; however, a better exposure could not be obtained. The screen is attached to the north wall of the tower, at an elevation of II feet above the ground, and about 200 feet above sea level.

It will be seen that there is the wall of a dwelling house at no great distance to the westward, which may possibly affect the instrument by radiation, and also interfere with the free circulation of the air.

STONYHURST. - The observatory stands in the centre of the college garden, which is on a gentle slope facing S.S.E., $38 \mathrm{I}$ feet above sea level. The anemograph stands on a cylindrical roof 12 feet in diameter and 4 feet 5 inches in height. The total height of the cups above the ground is 30 feet.

The country around, including the college grounds, is wooded, but not very thickly so, and the trees are in general sinall.

The nearest trees whose height could materially influence the anemograph are at a distance of about 200 yards, bearing from $\mathrm{N}$. by $\mathrm{W}$, to $\mathrm{N}$. by $\mathrm{E}$.

The main building of the college is placed at the N.W. of the ohservatory, at a distance of 193 yards, its angular height above the roof of the observatory being $1^{\circ} 37^{\prime}$, and bearings from N. by W. to W.N.W.

The nearest hill is the Longridge Fell, whose nearest point is about two miles from the college. It extends from $N$. by $W$. to $W$. by $N$., and its highest point is $4^{\circ} I^{\prime}$.

Pendle $\mathrm{Hill}$ is at five and a half miles distance E.N.E; height $2^{\circ} 5^{\prime}$. Between these hills the country is very open. To the eastward there are hills at about four miles distance, height about $\mathrm{I}^{\circ}$. To the S. and S.W. the land is low.

It will be seen from this that the anemograph is fairly well exposed to the different points of the compass.

The thermograph screen is attached to the north wall of the observatory, the bulbs are at an elevation of $7 \mathrm{ft}$. above the ground. The exposure is good.

KEW.- The observatory is situated in the old Deer Park at Richmond. It is a small building, which is well exposed to the wind, excepting on the west side, where there is a row of trees distant about 150 yards, which must materially affect the velocity of the wind. The country about is also well wooded.

The anemograph is placed on the dome.

The thermograph screen is attached to the north wall of the observatory within ten feet of the west end of that wall, at a height of ten feet above the ground, and about fifty above sea level. Its exposure is good.

We hope to take another opporsunity of reviewing the volume itself.

\section{ON THE RECENT SOLAR ECLIPSE*}

(Continued from page 233)

\section{II.-POLARISCOPIC OBSERVATIONS}

WITH regard to the polarisation experiments, by the kindness of Mr. Spottiswoode $I$ am enabled to show yor, in a very clear way, the raison a'être of the polariscopic observations made during this and former eclipses; but the polariscopic ground is a wide one, and it is not my intention to cover it to-night.

I have had this arrangement of lamp, reflector and prisms made so fhat you may see how the polariscope can determine the percentage of reflected light at different angles, and the direction of reflection. Assume this lamp to represent the sun, let this reflector close to the lamp represent a particle near the sun, reflecting light to us, we shall naturally have the light reflected at a much larger angle than if the reflector were close to the screen representing a particle in our own air. Having this idea of the angle of reflection in your minds, and the fact that the larger the angle under these conditions the more the polarisation, if you take this lamp, as I have said, to represent the sun, and this mirror to represent any particle, of whatever kind you choose to imagine, it is clear that in order to get the maximum polariscopic effect from that particle, you must have it so situated that it will reflect light at a considerable angle to the beam coming from this lamp.

Now it is clear that in order to polarise the beam most strongly, I must place the reflector close to our imaginary sun. If $I$ so place it as to represent a particle in our own atmosphere, the angle will be so small that the polarisation of the light will hardly be perceptible.

Here is our sunlight, which we will polarise at as great an angle as we can, by placing the reflector close to the imaginary sun, and send it through this magnificent prism which $\mathrm{Mr}$. Spottiswoode has been good enough to place at our disposal; and in the path of the beam I will place an object so that you determine whether there is polarised light. [Experiment.] You see there is considerable brilliancy in those colours; their brilliancy depending upon the amount of polarisation.

Now if, instead of having our reflector close to our imaginary sun to represent a particle in the sun's atmosphere, we place it near the screen to represent a particle in our own, in which case the angle is extremely small, the brilliancy of the colours will entirely disappear. You see it has disappeared. The colours, as colours, are distinguishable, but their brilliancy has gone.

That is the rationale of the polariscopic observations, which have been made on the occasion of the last eclipse with more elaboration than they ever were before. If we found the corona to be strongly polarised, this was held to be a great argument in favour of the cornna being a real solar appendage, an argument strengthened if the polarisation was also found to be radial. At present, however, a great many of the observations that have been made have not been received, and those that have been received are as discordant as those obtained in former eclipses, and therefore my account is an imperfect one, because I have not had an opportunity of discussing all these observations. Indeed, if I had, I should hesitate to give an opiniol: on the sub. ject. When Mr. Carrington saw that small corona in $185 \mathrm{I}$, and $\mathrm{Mr}$. Gillis saw that small corona in 1858 , neither of them traced any polarisation whatever; but when $M$. Liais saw that large coruna in 1868, which was invisible to $\mathrm{Mr}$. Gillis, he in his turn saw an immense amount of polarisation, which led him to believe that the corona was solar, the whole of it, rays and everything inclucled, and that we had an indication of a solar atmosphere two or three times higher than the diameter of the sun; that is, an atmosphere two or three millions of miles in height. This observation is not in accordance with the general conclusions from the drawings I have shown you; and let me add that the assumption of reflection at the sun is not without its difficulties, and that we have not yet traced reflected sunlight, even when the strongest polariscopic effects have been observed.

III.-AIRY's AND MädLER'S CONCLUSIONS AS THE RESUlTS of THE Pre-spectroscopic Observations

Before passing to the spectroscopic observations, I will state the conclusions at which the Astronomer Royal and M. Mädler arrived atter the observations of 1860 had been gathered together.

The Astronomer Royal, in a lecture delivered befure the British Association at Manchester in 1861 , stated that the assumption of an atmosphere extending to the moon explained the observation of Plantamour, which could, he thought, be explained

\footnotetext{
* Lecture delivered at the Royal Institution, Friday, March x7, 187x.
} 
in no other way, and he held also that the polarisation experiments seemed to show the same thing. The Astronomer Royal was content to find the reflection, which so many now insist must be at the sun, taking place somewhere between the earth and moon.

M. Mädler's verdict is in the same direction, and though he does not perhaps express so decided an opinion, he maintains that the atmosphere plays a principal part in the phenomenon; and after detailing experiments to show this, he remarks of the solar and atmospheric portions, "Both cover each other and unite in one phenomenon, so that the corona is a mixed phenomenon."

I shall shortly show you that the spectroscope, leaving the telescope out of consicleration, has taught us that this is true; though I shall not be able to show you that it is the whole truth; we are not yet in a position to do that. Mädler concludes his observations by remarking:- " We cannot share the doubts of those who are afraid to surround the sun with too many envelopes; neither do we find anything unnatural in the statement that the sun has as many atmospheres as Saturn has fings; but we gladly admit that we camnot yet say anything positive. We have here a large field of probabilities, and the decision may yet be distant."

We can speak with more certainty now!

\section{IV.-Spectroscotic Oeservations}

a.--Spectrinn of the Corona first observed by Tennant, Pegson, and Rayet

We now come to the consideration of those observations in which we are aided by a most powerful and our most recent ally, the spectroscope, first used on the eclipsed sun, as you know, in the eclipse of I868. You all know that in that year the question of the nature of red flames was for ever settled by $M$. Janssen, Major Tennant, Captain Herschel, and others, who observed that eclipse in the most admirable manner; but we have nothing to do with the red flames now, we have to do with something outside them.

Now, most of you are under the impression, and it was mine until the day before yesterday, that the only thing we learnt about the corona in the eclipse of $x 868$, was that its spectrum was a continuous one; and I need not tell anyone in this theatre that the assertion that it was continuous was one that was extremely embarrassing, and implied that we had something non-yaseous outside the red flames, which seemed very improbable to those who know anything about the subject. But some of you will no doubt remember that, besides Major Tennant, who made this observation, we had a French observer, M. Rayet, who gave us a diagram of the spectrum of one of the prominences, and Mr. Pogson, who has now been for some time in India, and is a well. known observer, who gave us, nominally as the spectrum of a prominence, a spectrum with some curious variaticns from $M$. Rayet's diagram.

I exhibit a copy of M. Rayet's diagram of the spectrum of a prominence, as he called it. At the bottom is what he considered as the spectrum of the lower portion of the prominence; while in the higher portion, where we get fewer lines, as he considered, is the spectrum of the higher portion of the prominence. The spectrum of the lower portion contains the lines $B, D, E$, and $F$, and some other lines, in all nine, while the spectrum of the upper part of the prominence, as he thought it, only contains three lines. It was at first difficult to account for these observations. In the first place, one could not understand the line $B$ being given, because I soon found that the line $\mathrm{B}$ was not seen as a bright line in the chromosphere spectrum ; it was clearly the line $\mathrm{C}$ that was intencled. Hence doubt was thrown on the other lines; it seemed as if M. Rayet was wrong throut his elongated lines $\mathrm{D}, \mathrm{E}$, and $\mathrm{F}$, and probably meant $\mathrm{C}$ near $D$ and $F$. And so it was explained-I am ashamed to say by myself-that there was no particular meaning in these elongated lines, except that the spectrum of the prominence some distance away from the sun was simplex than it was nearer the sun, as happens in all prominences, as we may now cletermine any day we choose to look at the sun by means of the spectroscope.

Now let us hear Mr. Pogson. He gave a diagram showing five lines in the spectrum of what he thought a prominence, and he writes:- "A faint light was seen (in the spectroscope), scarcely writes:-"A Aaint light was srom either dark or bright lines. While wondering at the dreary blank before me, and feeling intensely disappointed, some bright lines came gradually into view, reached a pretty considerable maximum brilliancy, and again faded away. Five of these lines were visible, but two decidedly superior to the rest. . . . The readings of the two brightest were secured. It struck me as strange that these brightest lines should appear at a part of the spectrum not corresponding to any very conspicuous dark lines in the solar spectrum. . . . [These lines are a little less refrangible than E.] The third line seen in order of brilliancy must have been either coincident with, or very near the place of the sodium line $D$, but it was much fainter than the two measured, while the fourth and fifth lines were extremely faint." [They were very faint and DOUBLED, and near F. I have seen F give way to $a$ double line in our hydrogen experiments, though $Y$ am not prepared to say this is an explanation of Mr. Pogson's observations.]

The fact that we have here the first observations of the spect. rum of the sun's corona is one beyond all doubt; and why $M$. Rayet and Mr. Pogson thought they were observing prominences when they were observing above them, is explained by a remark made by Captain Tupman, of the Royal Marine Artillery, who acted as jackal to Prof. Harkness, and picked out the brighter spots of the corona for his observation. Prof. Harkness observing the prominence bright lines, said to Captain Tupman, "You have turned the telescope on to a prominence; I want the corona." "No," said Captain Tupman, "I am giving you the corona as well as I can." It was certainly the corona in both cases. Here you see, dimly and darkly, the first outcome of the spectroscope on the nature of the corona; a record as fairly written as anything at the sun can write it; and I am more anxious to lay stress on these observations, since they have lain fallow for two years, and show the importance of observations, not only in extending our knowledge, but in explaining prior observations; and it is an additional reason for never rejecting an observation. What was, however, dim and dark in 1868, shone out brightly in 1869 , thanks to the skill of the American observers of the eclipse of that year.

\section{6.-Laboratory Experiments bearino on these Observations}

But before I proceed to refer to the admirable observations made in America during this eclipse, I wish to introduce you to some work which was commenced in 1868 , and has been done quite independently of eclipses. In a lecture which I delivered here about two years ago, I described to you some of the facts observed by the spectroscope in the bright-line region which had been spectroscopically determined to exist all round the sun, and which, as in it all the various coloured effects are seen in total eclipses, I had named the Chromosphere. It was clear that by the new method of observing this without any eclipse, by partially killing, so to speak, the atmospheric light, we got a percentage only of the phenomenon, as the atmospheric light could only be killed by an amount of dispersion which enfeebled and shortened the chromospheric lines; so that although we could say that an envelope of some 5,000 or 6,000 miles in height existed round the sun, we could not fix this as a maximum limit. Further, when we examined the spectrum of this envelope we got long lines and short lines; and $Y$ told how the short lines indicated a low stratum, and how a long line indicated a higher one. To explain this, I will show you an observation made long before the new method was thought of. Even before that time we had abum. dant evidence of such strata, if we could not determine their nature: we had distinct evidence either of one thing thinning out, and then another, or that various substances were situated at different levels, under clifferent conditions; on the first hypothesis, at the extreme outside of the chromosphere the last thing would thin out, and then there would be an end of all things as respects the sun.

I will show you a clrawing made by Prof. Schmidt of the eclipse of $185 \mathrm{I}$. I do not wish to call your attention to the strange shape of the large prominence, but to the fact, that as the moon passed over this region we get a thin red band, first along the edge of the dark moon, and after the moon had passed over still further, we see this red layer, suspendted as it were in the chronzosphere, with a white layer below it. This is the explanation of the long and short lines visible in the spectrum of the chromosphere ; in the red layer we have hydrogen almost alone below, its red light was conquered by other light with bright lines in all parts of the spectrum, and we get white light.

Lord Lindsay tells me he has a distinct indication, written by the sun himself, that in one particular part of the chromosphere, as recorded photographically in Spain, there were three such layers. And over and over again we find recorled white light close to the sun, then red alone, or red mixed with yellow, then violet, 
and lastly green. And M. Mädler remarks on this very admirably, "The violet band is the link between the prominences and the corona."

Before going further, I will show you the difference in the appearance of what we may term hot hydrogen and cold bydrogen, that is, hydrogen which we drive into different degrees of incandesceace by means of the spark. After Dr. Frankland and myself were able to determine that the pressure in these solar regions was small, we came to the conclusion that outside the hot hydrogen there must be some cooler hydrogen, in order that the phenomena we observed, both in the laboratory and in the observatory, should agree.

I have in this tube hydrogen at a certain pressure, and here we have a coil which will enable us to send a spark through it; you see we get a certain amount of redness in that tube, and if you look on one side or above you will see a sort of bluish-greenish light. Now that redness represents the condition of the hydrogen in the region of the sun where Dr. Schmidt gave us that extremely thin red ring, and the combination of the blue and red would give you something very like violet.

But here I have hydrogen under a different condition. In the tube its rareness is not excessive; but in this globe, of which I am about to speak, you have the nearest approach to a vacuum ever obtained through which a spark will pass; and I beg to call your attention to what will now happen. This globe contains the same chenical element prepared at the same time as the chemical element you have in the tube, but you see that, so far as colour goes, we have something perfectly different in this case. Now we send the spark through it. I would beg Prof. Tyndall, if he will be good enough, to observe the spectrum of this hydrogen in this globe. [Prof. Tyndall did so.] You will see that there is one line? [Prof. Tyndall: Yes.] And a continuous spectrum? [Prof. Tyndail: And a continuous spectrum.] Cool hydrogen gives us only the bright line F, plus a continuous spectrum, and many of you will know the extreme importance of that observation. It accounts for the $F$ line being observed without the $C$ line in 1868 and last year, and also for he continuous spectrum observed in the Indian eclipse.

$$
\text { c.-The American Eiclipse }
$$

When we come from the Indian to the American eclipse with the considerations to which I have drawn your attention, namely, the existence of these different layers due to the different elements and conditions of the same element thimning out, we shall see the extreme importance of the American observations, for they establish the fact that outside the hydrogen layer there was a layer giving only a line in the green, the line which Rayet and Pogson had observed associated with the hydroyen spectrum and the spectrum of the yellow substance. Here obviously we have, I think, merely an indication of another substance thinning out, in spite of the extraordinary suggestion which was pat forward that the corona was nothing but a permanent solar aurora.

I need hardly tell you that the idea of a permanent aurora anywhere was startling, and that of a permanent solar aurora more startling still ; but what I claim is, that during last year's observations we made this very startling idea into a most beautiful fact, namely, that this outer layer of the chromosphere is in all probability nothing more nor less than an indication of an element lighter than hydrogen, although this is not yet absolutely estabIished, for the line is coincident with one of the lines in the spec rum of iron.

\section{d.--The laycrs increase very rapidly in Density. Reproduction} of the Coloured Phenomena

Dr. Frankland and myself were early drawn to consider the solar nature of the large coronas, to which I have called your attention, as extremely questionable, even on the supposition of cool hydrogen, because we did not see how, with its temperature and pressure, it conld extend very far: and an experiment which I have to make here will probably make that clearer.

We have in these glass vessels hydrogen a little more brilliant now the spark passes through it than that you saw in the globe, because I have been compelled to mix with it a certain amount of mercury vapour. Below, we have at the present moment sodium vapour being generated from metallic sodium in one tube, and mercury vapour in the other. I hope, if the experiment succeeds, you will see that a good many of the coloured phenomena seen in the chromosphere during eclipses may be easily reproduced by such experiments as this; and not only the coloured phenomena but the increase of brilliancy accompanied by changes of colour recorded. You can now all see the yellow tinge at the bottom of one tube, and the green tinge at the bottom of the other; and if there were time to continue this experiment by increasing the densily of the vapours now associated with the hydrogen, I conld make the bottom portion of each tube where the vapours are densest shine out almost like the sun, while the cool hydrogen at the top would remain not more brilliant tizan it is at present. We should have as it were a section of the chromosphere.

\section{V.-CONCLUSron}

I will proceed now, if you will allow me, to some of the general results obtained during the last eclipse.

I think that, although the work has been very unfortunately interrupted, still the result has been most satisfactory. By putting together observations here and ohservations there, I consider our knowledge of the sun is enormously greater than it was a few months ago. For instance, we are enabled to understand the long-neglected observation of Rayet, and the equally long. neglected obiervation of Pogson; and we know that outside the hydrogen there is, in all probability, a new element existing in a state of almost infinite tenuity. And we are sure of the existence of cool hydrogen above the hot hydrogen, a fact which seemed to be negatived by the eclipse of 1869 .

I think if we had merty determined that there was this cool hydrogen, all our labour would not have been in vain, as it shows the rapid reduction of temperature. But there is more behind. I told you that M. Mädler, in summing up the observations made up to 1860 , came to the conclusion that part of the corona was certainly solar, and that whether the outer portions were or were not solar, was a matter of doubt. I do not say that we have settled that absolutely, but we have firm evidence that some of the light of the corona is due to reflexion between the earth and the moon. The outer corona was observed to have a rosy tinge over the prominences, and the spectrum of the prominences was detected many minutes above them, as well as on the dark moon. It could not have got this colvur at the swn, for its intrinsic colour is green, and the red light of the hydrogen supplied at the sun is abolished altogether, is absorbed, and can only reach the corona at the sun, so to speak, as dark light.

It is a great fact that we are sure, as far as observation can make us sure, that there is a glare round the hydrogen which gives us the spectrum of hot hydrogen on the corona, wollore we innowe that hat hydrogen does not exist. Assume the hot hydrogen which gives us the red light to be only two minutes high, the spectroscope has picked it up eight minutes from the sun! The region of cool hydrogen is exaggerated in the same way. We get it where there is no indication of the cool hydrogen existing. And then with regard to the element which gives us the line of the green, we get that twenty minutes or twenty-five minutes away from the sun. Well, no man who knows anything about the matter will affirm that it is certain that the element exists at that distance from the sun.

Therefore I think we have absolutely established the fact that as the sun-the uneclipsed sun--gives us a glare round it, so each layer of the chromosphere gives us a glare round it. That is exactly what was to be expected, and that it is true is proved by the observation - a most important observation made in Spainthat the air, the cloud, ever between us and the dark moon, gives us the same spectrum that we get from the prominences themselves.

Given, however, the layers and elements in the chromosphere extended as far as you will, and apparently increased or not by reflection not at the sum, we have still to account for rays, rifts, and the like. If anyone will explain either Mr. Brothers's photograph or Mr. Gilman's picture of the eclipse of 1869 , containing those dark bands starting from the moon and fading away into space, and the bright variously.coloured rays between them, on any solar theory, he will render great service to science. But in the meantime I must fall back upon M. Mädler's opinion of I860, with the addition to it that I have stated that we have found, at all events, that some of the doubtful light is non-solar ; we have turned the opinion into a fact

Bear in mind that close to the sun you have a white layer composed of vapours of many substances, including all the outer ones; outside this is a yellow region; above that a region of hydrogen, incandescent and red at the base, cooler, and therefore blue, higher up, the red and blue commingling and giving us violet; and then another element thinning out and giving us green. Take these colours in connection with those which are thrown on our landscapes or on the sea during eclipses, each region being lit up in turns with varying, more or less mono- 
chromatic light, and that light of the very colour composing the various layers, each layer being, as I have shown, so much brighter than the outer ones that its light predominates over them. Is it too much to suggest to those who may be anxious 10 attempt to elucidate this subject, that probably if they would consider all the conditions of the problem presented by that great screen, the moon, allowing each of these layers by turn to throw its light earthwards, the inequalities of the edge of the globular moon allowing here liyht to pass from a richer region, here stopping light from even the dimmer ones, they would be able to explain the rays, their colours, variations, apparent twistings, and change of side? I do not hesitale to ask this question, because it is a difficult one to answer, since the whole question is one of enormous difficulty. But difficult though it be, I urust I have shown you that we are on the right track, and that in spite of our bad weather. the observations made by the English and American Government Eclipse Expedition of 1870 have largely increased our knowledge.

With increase of knowledge generally comes a necessity for changing the nomenclature belonging to a time when it was imperfect. The researches to which I have drawn your attention form no exception to this rule. A few years ago our science was satisfied with the terms prominences, sierra, and corona, to represent the phenomena I have brought before jou, the nature of both being absolutely unknown, as is indicated by the fact that the term sierra was emploved, and aptly so, when it was imagined the prominences might be solar mountains! We nnw know many of the cunsti uent materials of the e strange thirgs; we know that we are dealing with the exterior portion of the solar atmosphere. and a large knowledge of solar meteorology is already acquired, which shows us the whole mechanism of these prominences. But we also know that part of the corona is not at the sun at all. Hence the terms leucosplitre and hato have been suggested to designate in the one case the regions where the general radiation, owing to a reduced pressure and temperature, is no longer subordinate to the selecrive radiation, and in the other, that part of the corona which is non-rolar. Neither of these terms is apt, nor is either necessary. Ail purposes will be served if the term corona be retained as a name for the exterior region, including the rays, ritts, and the like, about which doubt still exists, though it is now proved that some part is non-solar, while for the undoubted solar portion the term Chromospherethe bright-line region-as it was defined in this theatre now two years ago, exacily expresses its characteristic fcatures, and differentiates it frim the photosphere and the associated portion of the solar atmosphere.

Here my discourse would end, if it were not incumbent on me to state how gra eful I teel to Her Majesty's Guvernment for giving us the upportunity of going to the eclipse; to place on record the pleasure we all felt in being so closely assuciated in our work with the distinuuished American astronomers who from first to last aided us greatly; and to express our great gratirude to all sorts of new friends whom we found wherever we went and who welcomed us as if they had known us from our chldhood.

J. NURMAN LOCKYER

\section{ON THE DISTRIBUTION OF TEMPERATURE IN THE NORTH ATLANTIC*}

$A \mathrm{~T}$ the request of the Council of the Scottish Meteorological Sociely, I beg to bring before you a sketch of the more recent resulis of investigations into the causes of the abnormal climate of the surface of a great portion of the North Allantic Ocean, and of the lands which form its north-eastern borders; and especially the results of the deep-sea exploring expeditions of the last three years, in wh:ch $I$ have taken a part, so sar as they bear upon this point.

In a recent valuable report on the Gulf Stream in the "Geo. graphische Mittheilungen," of last year, Dr. Petermann severely and, I think, too justly, reflected upon us students of ocean temperatures for giving ourselves up to wild and gratuitous speculation. I wish, if possible, on the press nt uccaswen, to avoid all risk of such impeachment, by limiting our inquiry rigidly for the few minu es I have at my disposal to the present condition of our knowledge of facts, and to such deductions from these as may be fairly cunsidered proved.

* Actress deivered to the Meteorological Society of Scocland at the General Meting of the Society, July 5
Let us then first inquire for a moment what the phenomena are which we are callerl upon to correlate and to explain. There is no dispute about these facts, and a glarsce at the chart will at once recall them to your recollection. In the first place, the lines of equal mean annual temperature, instead of showing any tendency to coincide with the parallels of latitude, run up into the North Atlantic and into the North Sea, in the form of a series of long lonps. This cliver:ion of the isothermal lines from their normal direction is admirtedly caused by surface oceancurrents conveying the warm tropical water tuwards the polar regions, whence there is a constant counter-flow of cold water beneath to supply its place. This phenomenon is not confned to the North Atlantic. A corresponding series of looss, though not so well defined, passes southwards along the east coast of South America, and a very marked series occupies the northeattern angle of the Pacific, off the Aleutian Islands and the coast of California. The temperature of the land is not affected directly by the temperature of the sea in its immediate neighbourhood, but by the temperature of the prevailing wind, which is determined by that of the sea. Setting aside the still more important point of the equalisation of summer and winter temperature, the mean anmual temperature of Bergen, lar. $60^{\circ} 24^{\prime} \mathrm{N}$., subject to the ameliorating influtnce of the south-west wind blowing over the temperate water of the North Atlantic, is $6.7^{\circ} \mathrm{C}$. while that of Tobolsk, lat. $58^{\circ} 13^{\prime}$, is $-24^{\circ} \mathrm{C}$.

But the temperature of the North Atlantic is not only raised greatly above that of places on the same parallel of latitude having a continental climate by this inerchange of tropical and polar water, but it is gratly higher than that of places apparently similarly circumstanced as to a general interchange of water in the Southern Hemisphere. Tnus, the mean annual temperature of the Farce Islands, lat. $62^{\circ} 2^{\prime} \mathrm{N}$. is $7 \mathrm{I}^{\circ} \mathrm{C}$. nearly equal to that of the Falkland Islarids, lat. $52^{\circ} \mathrm{S}$., which is $82^{\circ} \mathrm{C}$., and the temperature of Dublin, lat. $53^{\circ} 2 \mathrm{I}^{\prime} \mathrm{N}$., is $9^{\circ} 6^{\circ} \mathrm{C}$., while that of Port Famine, lat. $53^{\circ} 8^{\prime} \mathrm{S}$, is $5.3^{\circ} \mathrm{C}$. A Again the high temperature of the North Atlantic is noc equally distributed, but is very marked in its special determination to the north-east coasts. Thus, the mean annual temperalure of Haifax, lat. $44^{\circ} 39^{\prime}$, is $6.2^{\circ} \mathrm{C}$, while that of Dublin, lat. $53^{n} 21^{\prime}$ is $9.6 \mathrm{C}$, and the temperature of Boston (Mass.) lat. $42^{\circ} 21^{\prime}$ is exactly the same as that of Dublin.

We thus arrive at the well-known general result, that the temperature of the sea bathing the north-east shores of the North Atlantic is greatly raised above its normal point by currents in. volving an interchange of tropical and polar water; and that the lands bordering on the $N_{1}$,rth Atlantic particivate in this ameliora. tion of climate by the heat imparted by the water to their prevailing winds.

We shall now examine this distribution of ocean temperature a little more minutely. During the last many years a prodigious amount of data have been accumulating with re:erence to the derailed distribution of heat on the surface of the No th Atlantic bisin, and last year M. Petermann, of Gotha. published in his "Geographische Mittheilungen" a series of invaluable temperature charts embodying the restlits of the reduction of upuards of 100,000 obseriations derived mainly from the following sources:-

I.t. From the wind and current charts of Lieut. Maury, emb: dying about 30,000 distinct tempcrature observations.

2nd. From 50,000 observations made by Dutch sea captains and published by the Government of the Netherlands.

3 rd. From the journal of the Cunard sttamers between Liverpool and New York, and of the steamers of the Montreal Company brtween Glasgow and Belleisle.

4 h. From the data collected by our excellent secretary, Mr. Buchan, with regard to the iemperature of the coast of Scolland.

5th. From the pablications of the Norwegian Institute on sea temperatures betwı en Norway, Scolland, and Iceland.

6th. From the data turnished by the Dani-h Rear-admiral Irminger on sea temperatures between Denmark and the Danish settlements in Greenland.

7th. From the observations made by Lord Dufferin on board his yacht Foan between Scotland, Iceland, Spilzbergen, and Norway.

And finally from the recent observations collected by the English, German, Swedish, anit Russian expeditions to the Arctic Reyions and towards the North Pole.

Di. Peiermann has devo ed the special attention of a great part of his life to this question, ard the accuracy of his results in every derail is beyonci the shadow of a duubt. Every curve of equal temperature, whether for the summer, for the winter, or for the 